\title{
The prognostic value of S100A10 expression in cancer (Review)
}

\author{
NORMASTUTI ADHINI TANTYO ${ }^{1}$, AZRINA SARASWATI KARYADI ${ }^{1}$, SITI ZULIMAS RASMAN $^{1}$, \\ MARVELMARIO REGINALD GABRIEL SALIM ${ }^{1}$, ASTRELLA DEVINA ${ }^{1}$ and ANTON SUMARPO ${ }^{2}$ \\ ${ }^{1}$ Department of Biomedicine, Indonesia International Institute for Life Sciences, Jakarta Timur 13210; \\ ${ }^{2}$ Department of Biochemistry, Faculty of Medicine and Health Sciences, Atma Jaya \\ Catholic University of Indonesia, Jakarta Utara 14440, Indonesia
}

Received January 29, 2018; Accepted November 15, 2018

DOI: $10.3892 / \mathrm{ol} .2018 .9751$

\begin{abstract}
S100A10, a member of the S100 protein family, commonly forms a heterotetrameric complex with Annexin A2. This is essential for the generation of cellular plasmin from plasminogen, which leads to a cascade of molecular events crucial for tumor progression. S100A10 upregulation has been reported in a number of cancers, suggesting that it may have potential as a prognostic biomarker, as well as predicting sensitivity to anticancer drugs. This review evaluates the direct and indirect relationships between S100A10 and cancer progression by investigating its role in cancer. Research papers published on PubMed and Google Scholar between 2007-2017 were collated and reviewed. We concluded that S100A10 affects the development of the hallmarks of cancer as explained by Hanahan and Weinberg in 2011, most notably by activating the invasion and metastasis of cancer cells. However, further studies are required to explore the underlying biological mechanisms of S100A10.
\end{abstract}

\section{Contents}

1. Introduction

2. Tumor-promoting activities of S100A10 in cancer

3. Conclusion and future studies

\section{Introduction}

Genomic analysis is an important tool used in the development of therapies against cancer. Current therapies for cancer often fail, which eventually leads to a high mortality rate. A study by

Correspondence to: Dr Anton Sumarpo, Department of Biochemistry, Faculty of Medicine and Health Sciences, Atma Jaya Catholic University of Indonesia, 2 Jl. Pluit Raya, Jakarta Utara 14440, Indonesia

E-mail: sumarpo01060715@gmail.com

Key words: S100A10, cancer, cancer progression, hallmarks of cancer, biomarker
Kim et al (2010) revealed that distinct subtypes of breast cancer exhibit different sensitivities to systemic chemotherapy (1). Causative gene mutations may also affect the sensitivity of cancer cells towards certain chemotherapeutic drugs (2), and so developing genomic biomarkers specific to each cancer subtype is essential for screening, diagnosis, predicting patient prognosis and selecting effective cancer treatments $(2,3)$.

S100A10, a member of the S100 proteins family, forms a homodimer comprising two EF-hand motifs; an N-terminal S100-specific EF hand and a C-terminal canonical EF hand, linked by a hinge region known as the $\mathrm{Ca}^{+}$-binding loop (4). The function of the EF hand remains elusive due to limited knowledge regarding its structural effects on downstream targets, despite thorough studies of the interaction between the EF hand and $\mathrm{Ca}^{2+}(5)$. Genetic mutations, such as substitutions and deletions, have been identified in the calcium-binding residues of the EF hand, which render S100A10 unable to bind to calcium (6). S100A10 has been reported to interact with numerous ion channels, such as TRPV5 and TRPV6 for $\mathrm{Ca}^{2+}$ and $\mathrm{Mg}^{2+}$ transport, as well as the serotonin 5-HT1B receptor, which is involved in the regulation of serotonin signaling (7). Additionally, the expression of S100A10 in epithelial and stromal cells of the endometrium might promote embryo implantation (8). Furthermore, S100A10 upregulation is involved in the progression of angiogenesis of the embryo (9). Based on these reports, it appears that S100A10 is involved in a variety of normal functions in several tissues via interactions with various biomolecules.

Annexin 2(ANXA2) is the most common ligand of S100A10, which, along with other ligands, forms a heterotetrameric complex known as AIIt (A2 heterotetramer). Several studies have reported that the ANXA2-S100A10 complex prevents ubiquitinylation of S100A10 (10,11). Allt is an essential regulator of cellular plasmin generation. Plasminogen circulates in the blood it its inactive form, and the conversion of S100A10-bound plasminogen to plasmin is mediated by tissue plasminogen activator (tPA) and urokinase-type plasminogen activator (uPA) (11-13). Binding to Allt prevents inactivation of the plasmin, which may eventually contribute to cancer progression (14-18).

\section{Tumor-promoting activities of S100A10 in cancer}

It has been established that cancer cells undergo modifications that make them functionally different to normal cells. 
These modifications result in certain characteristics, known as the 'Hallmarks of Cancer'. In 2011, Hanahan and Weinberg reported the hallmarks of cancer as well as the enabling characteristics of cancer cells, which are: i) Sustained proliferative signaling; ii) resistance to cell death; iii) evasion of growth suppressors; iv) replicative immortality; v) tumor-promoting inflammation; vi) avoidance of immune destruction, vii) angiogenesis induction; viii) invasion and metastasis activation; ix) deregulation of cellular energetics and $\mathrm{x}$ ) genome instability and mutations (19). In order to evaluate the role of S100A10 in cancer, the effects of S100A10 in the development of these hallmarks need to be investigated.

Sustained proliferative signaling, resistance to cell death, evasion of growth suppressors and replicative immortality. Tumor cells are considered to be persistent due to their ability to survive in unfavorable conditions, which is a result of the abovementioned modifications. This persistence be achieved by direct action via the release of their own growth factors, thus preserving autocrine signaling, or indirect action via interfering with the apoptotic pathway to inhibit apoptosis (19). The intrinsic apoptotic pathway, which involves the Bcl-2 family, regulates apoptosis through the mitochondria. Possible mechanisms by which $\mathrm{Bcl}-2$ family proteins regulate apoptosis have been postulated (20), however these mechanisms have yet to be definitely elucidated. It has been reported that Bad, a pro-apoptotic member of the Bcl-2 family, induces cytochrome $\mathrm{C}$ release from the mitochondria, activating caspase 9 which in turn leads to the activation of caspase-3 and the initiation of apoptosis (20). However, S100A10 has been reported to interact with Bad and hinder its pro-apoptotic activity, suggesting that S100A10 may have anti-apoptotic effects in cancer cells $(21,22)$. This may explain reports of increased caspase-3 expression following S100A10 downregulation in vitro (23) and in S100A10-knockout mice (24). Furthermore, S100A10 downregulation suppresses cell growth by reducing the expression of Cyclin D1 (24), which is the critical downstream effector protein of epidermal growth factor receptor (EGFR) signaling (25). It is important to note that S100A10 is overexpressed in patients with mutated EGFR in comparison to patients with normal EGFR, suggesting a correlation between the two (26). Reduced growth of murine Lewis lung carcinoma or T241 fibrosarcoma has also been reported in S100A10-deficient mice (12). In accordance with the in vivo evidence, the regulation of tumor cell proliferation by S100A10 has been observed in patients with a variety of cancers, including squamous cell carcinoma (27) and colorectal cancer (28), as well as in COLO201, COLO205, COLO320, DLD-1, HCT-15, HCT-116, HT29, LOVO, LS174T, SW480, SW620, SW1116 and WiDR colorectal cancer cell lines (22). Furthermore, reduced S100A10 expression caused by ANXA2 knockdown resulted in decreased tumor growth and proliferation in GL621 mouse glioma cells (29).

Tumor-promoting inflammation and avoidance of immune destruction. Inflammation is one of the critical traits that contributes to tumor progression and cancer development. Chronic inflammation is known to increase the incidence of cancer, primarily by causing DNA damage and inducing the inflammatory response, which give rise to a pro-tumorigenic microenvironment $(30,31)$. When tumor growth reaches a certain point, tumors begin to produce pro-inflammatory factors, predominantly matrix metalloproteinases (MMPs), which induce further inflammation at the tumor site. This results in further recruitment of immune cells and cytokine production, which in turn promotes tumor progression (32). This recurrent positive loop of inflammation in tumorigenesis is integral to the rapid progression of cancer.

Tumor cells regulate inflammation via various mechanisms, and S100A10 has been identified to serve a pro-inflammatory role. As discussed, AIIt converts plasminogen into plasmin, which may lead to inflammation. The amino-terminal peptide is a byproduct of plasmin cleavage (33). AIIt-derived cell surface plasmin triggers the phosphorylation of PKC signaling molecules, which leads to ANXA2 cleavage, resulting in the activation of toll-like receptor 4 (TLR-4) and NFKB signaling (34). This pathway has been reported in hepatocellular carcinoma, in which activation of the Akt/NFkB signaling pathway promoted liver carcinogenesis. AIIt disassembly occurs after ANXA2 phosphorylation, following which tPA binds to the S100A10 subunit within the carboxyl-terminal lysine residue, to activate the CD11b-dependent integrin-linked kinase (ILK) pathway $(13,35)$. Together with plasmin, ILK can induce nuclear translocation of $\mathrm{NF} \kappa \mathrm{B}$, which promotes the production of pro-inflammatory factors, including IL-1, IL-6 and TNF $\alpha(13,33,36)$. Although AIIt-dependent macrophage activation may occur via the MAPK and NFאB pathways, TLR-4 knockdown inhibits AIIt-driven cytokine production (16); this suggests that TLR-4 serves an important role in AIIt-mediated inflammation. TLR-4 activation induces tumor-associated IL-6 expression in bladder cancer through p38 and Erk signaling (37), which is activated by JAK1/TYK2 and STAT3 stimulation. Inhibiting JAK, p38, and $\mathrm{NF}_{\kappa} \mathrm{B}$ results in a significant reduction in IL- 6 and TNF- $\alpha$ expression, suggesting that this pathway is important for releasing plasmin-dependent cytokines (38).

TLR-4 activation triggers AIIt to recruit and activate macrophages (16) via extravasation and migration within extravascular tumor tissues. The effects of S100A10 in cellular migration and invasion may significantly contribute to the recruitment of immune cells at the tumor inflammation site by inducing fibrinolysis. It has been hypothesized that S100A10 expression in macrophages induces the production of plasmin by cell surface plasminogen receptors, which allows for the migration of macrophages by facilitating the proteolysis of basement membrane and extracellular matrices (21). S100A10 has also been observed to have a direct effect in macrophage infiltration in vivo; S100A10 ${ }^{-/}$mice exhibited a significant reduction in macrophage recruitment compared with wild type mice (39). In addition, S100A10 indirectly stimulates the release of MCP-1 under hypoxic conditions (40), which might aid in the recruitment of monocytes in the tumor microenvironment via chemotaxis (33).

Prolonged inflammation at the tumor site suppresses the anti-tumoral activities of immune cells due to the secretion of tumor-promoting cytokines, including IL-1, IL-6 and TNF- $\alpha$ (41). The release of these cytokines and prostaglandin $\mathrm{E}_{2}\left(\mathrm{PGE}_{2}\right)$ stimulates the infiltration of myeloid derived suppressor cells (MDSCs) into the tumor microenvironment (42). Infiltrating MDSCs elicit immunosuppressive 
effects via a number of mechanisms, such as inducing anergy in NK cells via membrane-bound TGF- $\beta$, STAT-5 activity and ARG-1. Furthermore, it can suppress the cytotoxicity of NK cells by inhibiting interferon- $\gamma$ (IFN- $\gamma$ ) production (43) and downregulating NKG2D, as is observed in glioma (44). TGF- $\beta$ also been reported to induce the activation of induced Treg (iTreg) cells by MDSC (45). Moreover, together with IL-6, TGF- $\beta$ is able to stimulate Th17 and enhance the pro-tumoral effects of MDSC (41). The binding of TNF- $\alpha$

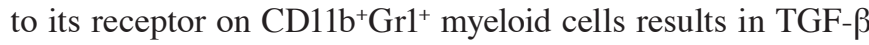
release, which in turn suppresses the anti-tumoral activity of $\mathrm{CD}^{+} \mathrm{T}$ cells (46), intensifying immunosuppression in the tumor microenvironment. S100A10's ability to release these pro-inflammatory cytokines indirectly facilitates immune-escape mechanisms by mitigating $\mathrm{T}$ cell cytotoxicity and evading immunosurveillance (36).

Angiogenesis induction. Due to its altered metabolism, the tumor microenvironment is hypoxic. This triggers the release of hypoxia inducible factor- $1 \alpha$ (HIF-1 $\alpha$ ), which stimulates oxygen delivery to the hypoxic site by promoting angiogenesis by regulating pro-angiogenic genes, including vascular endothelial growth factor (VEGF), platelet-derived growth factor (PDGF) and monocyte chemoattractant protein 1 (MCP-1) $(40,47)$. This results in increases in vascular permeability, endothelial cell proliferation and sprouting, creating a vast tumor vasculature (47). However, tumor vessels typically function poorly due to their irregular and leaky structure (48). Inadequate tumor vessels leads to the stabilization of HIF-1 $\alpha$, which further promotes angiogenesis to generate a positive feedback loop (47). The feedback loop is exacerbated by HIF-1 $\alpha$-induced ANXA2 transcription, which occurs via binding to the hormone response element of ANXA2 gene $(18,49)$. ANXA2 upregulation leads to the stabilization of S100A10 (10,18). Together, the heterotetrameric complex of ANXA2 and S100A10 enhances the generation of plasmin, which is able to activate a number of MMPs $(50,51)$. Both plasmin and MMPs further promote angiogenesis via the extracellular matrix (ECM) -associated pro-angiogenic growth factors $(36,52-54)$.

Studies have reported the significance of ANXA2 and S100A10 in the initiation and progression of angiogenesis. ANXA2-deficient mice exhibited decreased angiogenic activity $(55,56)$. This disturbance in angiogenic activity may occur due to the impaired plasmin-MMP axis of angiogenesis. Inhibition of heterotetramer formation via competitive binding results in a substantial reduction in vascular branching (57). It can therefore be inferred that the ANXA2-S100A10 complex plays a pivotal role in the initiation and progression of angiogenesis.

Cell-cell interactions are mediated by interactions between cancer cells and opposing endothelial cells via Annexin 2 and S100A10. This has been observed in breast cancer, where interactions between Annexin 2 and S100A10 resulted in the generation of activated plasmin, promoting ECM proteolysis and initiating the release of ECM-sequestered VEGF via MMP-9 activation $(13,58,59)$.

Activation of invasion and metastasis. Cancer malignancy is determined by its metastasis and invasion potential. This hallmark of cancer relies on the ability of cancer cells to modify ECM and induce epithelial to mesenchymal transition (EMT) (19). In order to invade and metastasize, cancer cells must cross the basement membrane. ECM is promoted by proteases, such as plasmin and MMPs (60). Plasmin proteolytic activity allows for the degradation of fibronectin and laminin within the basement membrane, simultaneously initiating a proteolytic cascade via the activation of proteases such as MMPs (61), which helps to remodel the ECM. An essential process in MMP regulation is the conversion of zymogen into active proteolytic enzyme, which is mediated by plasmin (62). S100A10 directly effects MMP regulation to influence plasmin generation. Following the binding of plasminogen to AIIt, the uPA-mediated generation and activation of plasmin upregulates MMP-1 via the Erk1/2, p38, cyclooxygenase-2 and $\mathrm{PGE}_{2}$ pathways (51). Specifically, extracellular AIIt allows cancer cells to utilize plasmin, cathepsin B and MMPs to degrade cellular adhesion factors (21). Plasmin-dependent ECM proteolysis activates $\mathrm{UPA}$, which binds to the UPA receptor (UPAR) to cleave and activate plasmin $(21,63)$. Activated plasmin subsequently activates pro-uPA, generating a positive feedback loop once again (21).

The positive feedback loop is intensified by pathways regulated by oncogenic Ras. It has been reported that oncogenic HRas upregulates MMP-2 and MMP-9 via increasing the expression of uPAR, suggesting that invasion and metastasis may be Ras-dependent. Although oncogenic Ras is a key regulator of plasmin generation, S100A10 knockdown results in a significant reduction in Ras-dependent plasmin generation (64). This verifies the existence of a positive feedback loop between S100A10, plasmin generation and oncogenic Ras. S100A10 overexpression has been reported to induce invasion and metastasis in lung adenocarcinoma and is correlated with higher TNM stages (65), thyroid neoplasms (66) and acute promyelocytic leukemia (APL) (36). S100A10 overexpression is observed in the breast cancer cell line MDA-MB-435 (67) and colorectal cancer (28). S100A10 downregulation, on the other hand, reduces plasmin generation, which leads to a loss of invasiveness of cancer cells (67).

S100A10 is an independent prognostic biomarker for serous ovarian cancer. A previous study reported that high S100A10 mRNA levels and S100A10 cytoplasmic positivity was correlated with decreased overall patient survival and a 2-fold increase in ovarian cancer mortality (68). In APL patients, S100A10 overexpression and activation promotes the migration of cancerous leukemic cells as well as hyperfibrinolysis, often causing excessive bleeding (13). One study reported that the AIlt overexpression resulted in forced expression of leukemia/retinoic acid receptor a (PML/RAR $\alpha)$ fusion protein, which led to a $27.6 \%$ increase in cell invasiveness, whereas antibodies inhibiting Allt reduced invasion and migration (36). It has been reported that the invasion of CCL-222 colorectal cells via ECM degradation was significantly reduced by a loss of S100A10 (69). S100A10 knockdown in HT-1080 cells results in the depletion of metastatic lung foci, whereas S100A10 upregulation increases the metastatic potential of these cells (61).

DLC-1, a Rho GTPase-activating protein, is a ligand that competitively binds wit S100A10 at the ANXA2 binding site. The coupling of S100A10 and DCL-1 prevents ANXA2 from 
inhibiting the ubiquitin-dependent degradation of S100A10, resulting in a decrease in S100A10 and, consequently, reduced migration and invasion in non-small-cell lung cancer lines (A549 and H1395) (70). This confirms that plasmin generation and plasminogen-dependent cell invasion occurs due to the surface protein loss of S100A10, not ANXA2. However, ANXA2 expression has been reported to be an independent predictor of metastasis in clear-cell renal cell carcinoma. It was demonstrated that the 5-year metastasis-free rate is significantly lower in ANXA2-negative tumors compared with ANXA2-positive tumors (71). As ANXA2 expression is proportional to S100A10 expression $(10,18,29)$, and S100A10 is highly expressed in renal cancer (72), it could be that renal cancer metastasis is initiated by the interaction between S100A10 and ANXA2. This has also been suggested in pancreatic (73) and gastric cancers $(38,74,75)$. S100A10 expression is increased in advanced pancreatic tumors compared with benign pancreatic tumors (15) and, furthermore, is correlated with the proportion of lymph node metastases and the depth of gastric cancer (38). However, the exact mechanism of S100A10 in cancer invasiveness requires further investigation. ANXA2 has been found to have an invasion-promoting role in in pancreatic ductal adenocarcinoma, which is achieved via the initiation of hedgehog signaling, inducing the binding of tenascin C to ANXA2 (76).

Deregulating cellular energetics. One of the factors that allow cancer cells to survive in unfavorable conditions is their ability to alter metabolic processes (19). Altered metabolism in cancer cells occurs via upregulation of glucose transporter 1 (GLUT1), which results in an elevated glucose intake to support energy production (77-79). A direct role of S100A10 in altering cellular metabolism has not yet been identified; however, the aforementioned metabolism dysregulation is highly associated with oncogenic Ras and HIF-1 $\alpha(77,78)$, suggesting an indirect effect of S100A10. As discussed above, S100A10 influences oncogenic Ras expression and HIF-1 $\alpha$ stabilization, resulting in KRas mutations that cause GLUT1 upregulation and consequently increased glucose uptake (80). As well as S100A10-mediated HIF-1 $\alpha$ stabilization, Ras activation also induces HIF-1 $\alpha$ translation via the Ras/Raf/Mek/Erk kinase signaling cascade (81). HIF-1 $\alpha$ then binds to hypoxia-response elements in the promoter region of the GLUT1 gene to increase GLUT1 expression (80).

In ovarian cancer, S100A10 has eight potential binding motifs for c-Myc transcriptional factor (82), which play an important role in the regulation of glycolysis via targeting the lactate dehydrogenase A (LDHA) (83). Overexpression and stabilization of c-Myc by S100A10 amplifies glycolysis, resulting in a persistent increase in the availability of nutrients necessary for cancer cell proliferation. There is a clear correlation between S100A10 expression and altered metabolism in tumor cells. However, further studies are required in order to explore the potential mechanisms by which S100A10 may directly affect tumor cellular energetics.

Genome instability and mutation. The hallmarks and characteristics of cancer develop via genetic or epigenetic modifications. Simply put, these modifications allow tumor cells to gain abilities that are beneficial for their growth. The underlying mechanism by which tumor cells obtain these characteristics is via mutations in caretaker genes. However, tumorigenesis may also be initiated by epigenetic changes that result in a downregulation of tumor suppressor genes (19). The location of the S100A10 gene is susceptible to epigenetic changes that may contribute to cancer development. These changes may affect the regulation of S100A10 expression, which corresponds to tumor malignancies (84).

No direct correlation between S100A10 and genomic changes has been identified. Nonetheless, its interaction with ANXA2 is associated with increased susceptibility to human papilloma virus (HPV) infection (85-87), in which integration of the viral genome into the host causes the degradation of p53 and $\mathrm{Rb}(88,89)$.

\section{Conclusion and future studies}

S100A10 is a novel gene that may have potential as a biomarker and treatment target due to its persistent overexpression in a variety of tumor cells, as well as its contribution to several key hallmarks of cancer. Recently, S100A10 expression has been recognized as a potential malignancy biomarker in colorectal cancer (28), renal cell carcinoma (72), non-small cell lung carcinoma (90) and gallbladder cancer (91).

It is thought that S100A10 might play role in cellular differentiation and cell cycle progression, making it a potent prognostic biomarker and a potential predictive marker of sensitivity to chemotherapeutic drugs. Oxaliplatin-based chemotherapy, which hinders the growth and proliferation of advanced cancer by activating certain apoptotic pathways, has been reported to be less effective in colorectal cancer with forced expression of S100A10 (47). Forced S100A10 expression significantly increases the $50 \%$ inhibitory concentration (IC50) of oxaliplatin (22). This suggests that S100A10 expression may be used to predict resistance to chemotherapeutic agents.

S100A10s is often expressed together with ANXA2, whose role in cancer has been well studied, as a heterotetramer complex localized in the intracellular cytoplasm and extracellular membrane of various cancer cells $(13,16,49)$. Despite the observed correlation between S100A10 expression and cancer development, little is known with regard to the underlying biological mechanisms.

In summary, this review demonstrates that S100A10 interacts with a variety of proteins in different pathways to promote cancer development (Fig. 1). One of the persistent roles of S100A10 that contributes to the hallmarks of cancer is plasmin generation, which significantly remodels the ECM $(13,61)$; this ECM modulation occurs in invasion, metastasis, inflammation, evasion of immune destruction, and angiogenesis. Furthermore, S100A10 appears to serve a greater role in the activation of invasion and metastasis compared with the other hallmarks of cancer (Table I). These findings may provide a basis for the development of effective treatment regimes for advanced cancer.

\section{Acknowledgements}

Not applicable.

\section{Funding}

No funding was received. 
Table I. Association between S100A10 expression and the hallmarks of cancer in different cancer types.

\begin{tabular}{|c|c|c|c|c|c|c|}
\hline \multirow[b]{2}{*}{$\begin{array}{l}\text { Types of } \\
\text { cancer }\end{array}$} & \multicolumn{6}{|c|}{ Hallmarks of cancer } \\
\hline & $\begin{array}{l}\text { Apoptosis and } \\
\text { proliferation }\end{array}$ & $\begin{array}{l}\text { Immune escape and } \\
\text { tumor-promoting } \\
\text { inflammation }\end{array}$ & Angiogenesis & $\begin{array}{l}\text { Invasion and } \\
\text { metastasis }\end{array}$ & $\begin{array}{l}\text { Cellular } \\
\text { energetics } \\
\text { deregulation }\end{array}$ & $\begin{array}{c}\text { Genome } \\
\text { instability } \\
\text { and mutation }\end{array}$ \\
\hline Breast & & & $\sqrt{ }$ & $\sqrt{ }$ & & \\
\hline Colorectal & $\sqrt{ }$ & & & $\sqrt{ }$ & & \\
\hline Gastric & & & & $\sqrt{ }$ & & \\
\hline Glioma & $\sqrt{ }$ & $\sqrt{ }$ & & & & \\
\hline Leukemia & & & & $\sqrt{ }$ & & \\
\hline Liver & & $\sqrt{ }$ & & & & \\
\hline Lung & $\sqrt{ }$ & & & $\sqrt{ }$ & & \\
\hline Ovarian & & & & $\sqrt{ }$ & $\sqrt{ }$ & \\
\hline Pancreas & & & & $\sqrt{ }$ & & \\
\hline Renal & & & & $\sqrt{ }$ & & \\
\hline SCC & $\sqrt{ }$ & & & & & \\
\hline Thyroid & & & & $\sqrt{ }$ & & \\
\hline
\end{tabular}

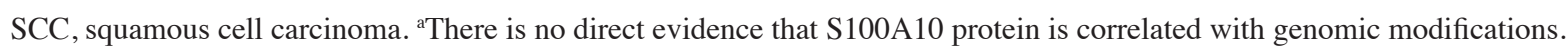

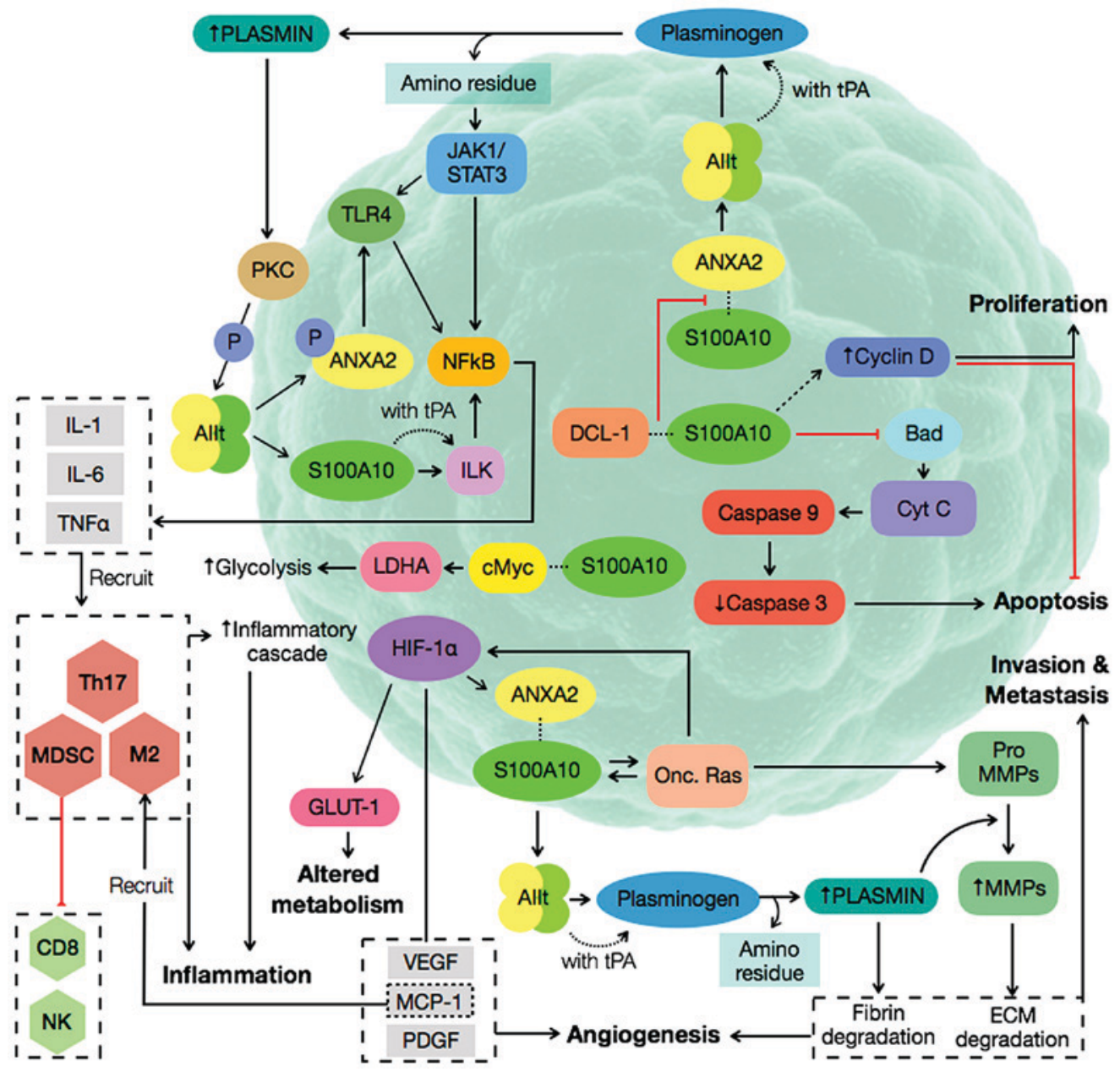

Figure 1. Cancer progression pathways involving S100A10. AIIt, Annexin A2 and S100A10 heterotetrameric complex; ANXA2, Annexin A2; CD8, CD8 ${ }^{+} \mathrm{T}$ cells; Cyt C, Cytochrome C; c-Myc; HIF-1 $\alpha$, Hypoxia inducible factor-1 $\alpha$; IL-1, interleukin 1; IL-6, Interleukin 6; ILK, integrin-linked kinase; M2, type 2 macrophages; LDHA, lactate dehydrogenase A; MCP-1, monocyte chemoattractant protein 1; MDSC, myeloid-derived suppressor cells; MMPs, matrix metalloproteinases; $\mathrm{NFKB}$, nuclear factor $\mathrm{\kappa B}$; NK, natural killer cells; Onc. Ras, oncogenic Ras; P, phosphate; PDGF, platelet derived growth factor; PKC, protein kinase C; Th17, T helper 17 cells; TLR4, toll-like receptor 4; TNF- $\alpha$, tumor necrosis factor $\alpha$; tPA, tissue plasminogen activator; VEGF, vascular endothelial growth factor. 


\section{Availability of data and materials}

Not applicable.

\section{Authors' contributions}

NAT and ASK devised the main conceptual ideas and proof outline. ASK designed the figures. NAT, ASK, SZR, MRGS and $\mathrm{AD}$ interpreted the results and drafted the manuscript. NAT took the lead in writing the manuscript. AS supervised the project, took part in the conceptualization of the whole manuscript and helped with the interpretations of the results obtained during the research process. In addition, AS also revised the manuscript thoroughly prior to submission and gave the final approval for its submission to be published.

\section{Ethics approval and consent to participate}

Not applicable.

\section{Patient consent for publication}

Not applicable.

\section{Competing interests}

The authors declare that they have no competing interests.

\section{References}

1. Kim SI, Sohn J, Koo JS, Park SH, Park HS and Park BW: Molecular subtypes and tumor response to neoadjuvant chemotherapy in patients with locally advanced breast cancer. Oncology 79: 324-330, 2010.

2. Novelli G, Ciccacci C, Borgiani P, Papaluca Amati M and Abadie E: Genetic tests and genomic biomarkers: Regulation, qualification and validation. Clin Cases Miner Bone Metab 5: 149-154, 2008.

3. Jin H, Lee HC, Park SS, Jeong YS and Kim SY: Serum cancer biomarker discovery through analysis of gene expression data sets across multiple tumor and normal tissues. J Biomed Inform 44: 1076-1085, 2011

4. Donato R, Cannon BR, Sorci G, Riuzzi F, Hsu K, Weber DJ and Geczy CL: Functions of S100 proteins. Curr Mol Med 13: 24-57, 2013.

5. Chazin WJ: Relating form and function of EF-hand calcium binding proteins. Acc Chem Res 44: 171-179, 2011.

6. Santamaria-Kisiel L and Shaw GS: Identification of regions responsible for the open conformation of S100A10 using chimaeric S100A11-S100A10 proteins. Biochem J 434: 37-48, 2011.

7. Svenningsson P and Greengard P: p11 (S100A10)-an inducible adaptor protein that modulates neuronal functions. Curr Opin Pharmacol 7: 27-32, 2007.

8. Bissonnette L, Drissennek L, Antoine Y, Tiers L, Hirtz C, Lehmann S, Perrochia H, Bissonnette F, Kadoch IJ, Haouzi D and Hamamah S: Human S100A10 plays a crucial role in the acquisition of the endometrial receptivity phenotype. Cell Adhes Migr 10: 282-298, 2016.

9. Domínguez F, Garrido-Gómez T, López JA, Camafeita E, Quiñonero A, Pellicer A and Simón C: Proteomic analysis of the human receptive versus non-receptive endometrium using differential in-gel electrophoresis and MALDI-MS unveils stathmin 1 and annexin A2 as differentially regulated. Hum Reprod 24 2607-2617, 2009

10. He KL, Deora AB, Xiong H, Ling Q, Weksler BB, Niesvizky R and Hajjar KA: Endothelial cell annexin A2 regulates polyubiquitination and degradation of its binding partner S100A10/p11. J Biol Chem 283: 19192-19200, 2008.

11. O'Connell PA, Madureira PA, Berman JN, Liwski RS and Waisman DM: Regulation of S100A10 by the PML-RAR- 0 oncoprotein. Blood 117: 4095-4105, 2011.
12. Phipps KD, Surette AP, O'Connell PA and Waisman DM: Plasminogen receptor S100A10 is essential for the migration of tumor-promoting macrophages into tumor sites. Cancer Res 71: 6676-6683, 2011.

13. Bharadwaj A, Bydoun M, Holloway R and Waisman D: Annexin A2 heterotetramer: Structure and function. Int J Mol Sci 14: 6259-6305, 2013.

14. Carpenter SL and Mathew P: Alpha2-antiplasmin and its deficiency: Fibrinolysis out of balance. Haemophilia 14: 1250-1254, 2008.

15. Sitek B, Sipos B, Alkatout I, Poschmann G, Stephan C, Schulenborg T, Marcus K, Lüttges J, Dittert DD, Baretton G, et al: Analysis of the pancreatic tumor progression by a quantitative proteomic approach and immunhistochemical validation. J Proteome Res 8: 1647-1656, 2009.

16. Swisher JF, Burton N, Bacot SM, Vogel SN and Feldman GM: Annexin A2 tetramer activates human and murine macrophages through TLR4. Blood 115: 549-558, 2010.

17. Miles LA and Parmer RJ: S100A10: A complex inflammatory role. Blood 116: 1022-1024, 2010.

18. Huang B, Deora AB, He KL, Chen K, Sui G, Jacovina AT, Almeida D, Hong P, Burgman P and Hajjar KA: Hypoxia-inducible factor-1 drives annexin A2 system-mediated perivascular fibrin clearance in oxygen-induced retinopathy in mice. Blood 118: 2918-2929, 2011.

19. Hanahan D and Weinberg RA: Hallmarks of cancer: The next generation. Cell 144: 646-674, 2011

20. Duronio RJ and Xiong Y: Signaling pathways that control cell proliferation. Cold Spring Harb Perspect Biol 5: a008904, 2013.

21. Madureira PA, O'Connell PA, Surette AP, Miller VA and Waisman DM: The biochemistry and regulation of S100A10: A multifunctional plasminogen receptor involved in oncogenesis. J Biomed Biotechnol 2012: 353687, 2012

22. Suzuki S and Tanigawara Y: Forced expression of S100A10 reduces sensitivity to oxaliplatin in colorectal cancer cells. Proteome Sci 12: 26, 2014.

23. Shan X, Miao Y, Fan R, Qian H, Chen P, Liu H, Yan X, Li J and Zhou F: MiR-590-5P inhibits growth of HepG2 cells via decrease of S100A10 expression and inhibition of the Wnt pathway. Int J Mol Sci 14: 8556-8569, 2013.

24. Egeland M, Warner-Schmidt J, Greengard P and Svenningsson P: Neurogenic effects of fluoxetine are attenuated in p11 (S100A10) knockout mice. Biol Psychiatry 67: 1048-1056, 2010.

25. Liu W, Ren H, Ren J, Yin T, Hu B, Xie S, Dai Y, Wu W, Xiao Z, Yang $\mathrm{X}$ and Xie D: The role of EGFR/PI3K/Akt/cyclinD1 signaling pathway in acquired middle ear cholesteatoma. Mediators Inflamm 2013: 651207, 2013.

26. Johnson H, Del Rosario AM, Bryson BD, Schroeder MA, Sarkaria JN and White FM: Molecular characterization of EGFR and EGFRvIII signaling networks in human glioblastoma tumor xenografts. Mol Cell Proteomics 11: 1724-1740, 2012

27. Li J, Riau AK, Setiawan M, Mehta JS, Ti SE, Tong L, Tan DT and Beuerman RW: S100A expression in normal corneal-limbal epithelial cells and ocular surface squamous cell carcinoma tissue. Mol Vis 17: 2263-2271, 2011.

28. Shang J, Zhang Z, Song W, Zhou B, Zhang Y, Li G and Qiu S: S100A10 as a novel biomarker in colorectal cancer. Tumour Biol 34: 3785-3790, 2013.

29. Wang CY and Lin CF: Annexin A2: Its molecular regulation and cellular expression in cancer development. Dis Markers 2014: 308976, 2014

30. Grivennikov SI, Greten FR and Karin M: Immunity, inflammation, and cancer. Cell 140: 883-899, 2010.

31. Neurath MF and Finotto S: IL-6 signaling in autoimmunity, chronic inflammation and inflammation-associated cancer. Cytokine Growth Factor Rev 22: 83-89, 2011.

32. Dufour A and Overall CM: Missing the target: Matrix metalloproteinase antitargets in inflammation and cancer. Trends Pharmacol Sci 34: 233-242, 2013.

33. Godier A and Hunt BJ: Plasminogen receptors and their role in the pathogenesis of inflammatory, autoimmune and malignant disease. J Thromb Haemost 11: 26-34, 2013.

34. Hajjar KA: The Biology of Annexin A2: From vascular fibrinolysis to innate immunity. Trans Am Clin Climatol Assoc 126: 144-155, 2015.

35. Hoesel B and Schmid JA: The complexity of NF- $\mathrm{BB}$ signaling in inflammation and cancer. Mol Cancer 12: 86, 2013.

36. Huang D, Yang Y, Sun J, Dong X, Wang J, Liu H, Lu C, Chen X, Shao J and Yan J: Annexin A2-S100A10 heterotetramer is upregulated by PML/RAR $\alpha$ fusion protein and promotes plasminogen-dependent fibrinolysis and matrix invasion in acute promyelocytic leukemia. Front Med 11: 410-422, 2017. 
37. Qian Y, Deng J, Xie H, Geng L, Zhou L, Wang Y, Yin S, Feng X and Zheng S: Regulation of TLR4-induced IL-6 response in bladder cancer cells by opposing actions of MAPK and PI3K signaling. J Cancer Res Clin Oncol 135: 379-386, 2009.

38. Li C, Hou Y, Zhang J and Zhang L: The expressions and roles of S100A6 and S100A10 in gastric cancer. Biomed Res 28 2131-2138, 2017

39. O'Connell PA, Surette AP, Liwski RS, Svenningsson P and Waisman DM: S100A10 regulates plasminogen-dependent macrophage invasion. Blood 116: 1136-1146, 2010.

40. Kaelin WG Jr and Ratcliffe PJ: Oxygen sensing by metazoans: The central role of the HIF hydroxylase pathway. Mol Cell 30: 393-402, 2008

41. Liu Y and Cao X: Immunosuppressive cells in tumor immune escape and metastasis. J Mol Med (Berl) 94: 509-522, 2016.

42. Bhatia A and Kumar Y: Cellular and molecular mechanisms in cancer immune escape: A comprehensive review. Expert Rev Clin Immunol 10: 41-62, 2014.

43. Han J, Alvarez-Breckenridge CA, Wang QE and Yu J: TGF- $\beta$ signaling and its targeting for glioma treatment. AM J Cancer Res 5: 945-955, 2015.

44. Crane CA, Han SJ, Barry JJ, Ahn BJ, Lanier LL and Parsa AT: TGF-beta downregulates the activating receptor NKG2D on NK cells and CD8+ T cells in glioma patients. Neuro Oncol 12: 7-13, 2010.

45. Lindau D, Gielen P, Kroesen M, Wesseling P and Adema GJ: The immunosuppressive tumour network: Myeloid-derived suppressor cells, regulatory $\mathrm{T}$ cells and natural killer T cells. Immunology 138: 105-115, 2013.

46. Terabe $M$ and Berzofsky JA: The role of NKT cells in tumor immunity. Adv Cancer Res 101: 277-348, 2008.

47. Krock BL, Skuli N and Simon MC: Hypoxia-induced angiogenesis: Good and evil. Genes Cancer 2: 1117-1133, 2011.

48. Siemann DW: The unique characteristics of tumor vasculature and preclinical evidence for its selective disruption by Tumor-vascular disrupting agents. Cancer Treat Rev 37: 63-74, 2011.

49. Luo M and Hajjar KA: Annexin A2 system in human biology: Cell surface and beyond. Semin Thromb Hemost 39: 338-346, 2013.

50. Bydoun M and Waisman DM: On the contribution of S100A10 and annexin A2 to plasminogen activation and oncogenesis: An enduring ambiguity. Future Oncol 10: 2469-2479, 2014.

51. Deryugina EI and Quigley JP: Cell surface remodeling by plasmin: A new function for an old enzyme. J Biomed Biotechnol 2012: 564259, 2012.

52. van Hinsbergh VW and Koolwijk P: Endothelial sprouting and angiogenesis: Matrix metalloproteinases in the lead. Cardiovasc Res 78: 203-212, 2008.

53. Montuori N and Ragno P: Role of uPA/uPAR in the modulation of angiogenesis. Chem Immunol Allergy 99: 105-122, 2014.

54. Kumari S and Malla R: New Insight on the role of plasminogen receptor in cancer progression. Cancer Growth Metastasis 8: 35-42, 2015.

55. Surette AP, Madureira PA,Phipps KD, Miller VA, Svenningsson $P$ and Waisman DM: Regulation of fibrinolysis by S100A10 in vivo. Blood 118: 3172-3181, 2011.

56. Liu W and Hajjar KA: The annexin A2 system and angiogenesis. Biol Chem 397: 1005-1016, 2016.

57. Valapala M, Thamake SI and Vishwanatha JK: A competitive hexapeptide inhibitor of annexin A2 prevents hypoxia-induced angiogenic events. J Cell Sci 124: 1453-1464, 2011.

58. Vempati P, Mac Gabhann F and Popel AS: Quantifying the proteolytic release of extracellular matrix-sequestered VEGF with a computational model. PLoS One 5: e11860, 2010.

59. Myrvang HK, Guo X, Li C and Dekker LV: Protein interactions between surface annexin A2 and S100A10 mediate adhesion of breast cancer cells to microvascular endothelial cells. FEBS Lett 587: 3210-3215, 2013.

60. López-Soto A, Gonzalez S, Smyth MJ and Galluzzi L: Control of Metastasis by NK Cells. Cancer Cell 32: 135-154, 2017.

61. Surette A and Waisman D: S100A10: A Key Regulator of Fibrinolysis. Fibrinolysis Thrombolysis, 2014.

62. Kessenbrock K, Plaks V and Werb Z: Matrix metalloproteinases: Regulators of the tumor microenvironment. Cell 141: 52-67,2010.

63. Hitchcock JK, Katz AA and Schäfer G: Dynamic reciprocity: The role of annexin A2 in tissue integrity. J Cell Commun Signal 8: 125-133, 2014

64. Madureira PA, Bharadwaj AG, Bydoun M, Garant K, O'Connell P, Lee $\mathrm{P}$ and Waisman DM: Cell surface protease activation during RAS transformation: Critical role of the plasminogen receptor, S100A10. Oncotarget 7: 47720-47737, 2016.
65. Katono K, Sato Y, Jiang SX, Kobayashi M, Saito K, Nagashio R, Ryuge S, Satoh Y, Saegusa M and Masuda N: Clinicopathological significance of S100A10 expression in lung adenocarcinomas. Asian Pac J Cancer Prev 17: 289-294, 2016.

66. Ito Y, Arai K, Nozawa R, Yoshida H, Higashiyama T, Takamura Y, Miya A, Kobayashi K, Kuma K and Miyauchi A: S100A10 expression in thyroid neoplasms originating from the follicular epithelium: Contribution to the aggressive characteristic of anaplastic carcinoma. Anticancer Res 27: 2679-2683, 2007.

67. Zhang J, Guo B, Zhang Y, Cao J and Chen T: Silencing of the annexin II gene down-regulates the levels of S100A10, c-Myc and plasmin and inhibits breast cancer cell proliferation and invasion. Saudi Med J 31: 374-381, 2010

68. Lokman NA, Pyragius CE, Ruszkiewicz A, Oehler MK and Ricciardelli C: Annexin A2 and S100A10 are independent predictors of serous ovarian cancer outcome. Transl Res 171: 83-95.e2, 2016

69. O'Connell PA and Waisman DM: Regulation of plasmin generation by the annexin A2 heterotetramer: A shift in perspective. Future Oncol 8: 763-765, 2012.

70. Yang X, Popescu NC and Zimonjic DB: DLC1 interaction with S100A10 mediates inhibition of in vitro cell invasion and tumorigenicity of lung cancer cells through a RhoGAP-independent mechanism. Cancer Res 71: 2916-2925, 2011.

71. Ohno Y, Izumi M, Kawamura T, Nishimura T, Mukai K and Tachibana M: Annexin II represents metastatic potential in clear-cell renal cell carcinoma. Br J Cancer 101: 287-294, 2009.

72. Domoto T, Miyama Y, Suzuki H, Teratani T, Arai K, Sugiyama T, Takayama T, Mugiya S, Ozono S and Nozawa R: Evaluation of S100A10, annexin II and B-FABP expression as markers for renal cell carcinoma. Cancer Sci 98: 77-82, 2007.

73. Yamamoto N, Nakamura Y, Morinaga S, Numata K, Sawazaki S, Watanabe T, Numata M, Tamagawa H, Godai T, Shiozawa M, et al: The clinical significance of S100A10 in pancreatic cancer. J Clin Oncol 31: 194, 2013.

74. Liu J, Li X, Dong GL, Zhang HW, Chen DL, Du JJ, Zheng JY, Li JP and Wang WZ: In silico analysis and verification of S100 gene expression in gastric cancer. BMC Cancer 8: 261, 2008.

75. Zhang Q, Zhu M, Cheng W, Xing R, Li W, Zhao M, Xu L, $\mathrm{Li}$ E, Luo G and Lu Y: Downregulation of $425 \mathrm{G}>$ a variant of calcium-binding protein S100A14 associated with poor differentiation and prognosis in gastric cancer. J Cancer Res Clin Oncol 141: 691-703, 2015.

76. Foley K, Muth S, Jaffee E and Zheng L: Hedgehog signaling stimulates Tenascin $C$ to promote invasion of pancreatic ductal adenocarcinoma cells through Annexin A2. Cell Adhes Migr 11: 514-523, 2017.

77. DeBerardinis RJ, Lum JJ, Hatzivassiliou G and Thompson CB: The biology of cancer: Metabolic reprogramming fuels cell growth and proliferation. Cell Metab 7: 11-20, 2008.

78. Jones RG and Thompson CB: Tumor suppressors and cell metabolism: A recipe for cancer growth. Genes Dev 23: 537-548, 2009.

79. Labak CM, Wang PY, Arora R, Guda MR, Asuthkar S, Tsung AJ and Velpula KK: Glucose transport: Meeting the metabolic demands of cancer and applications in glioblastoma treatment. Am J Cancer Res 6: 1599-1608, 2016.

80. Barron CC, Bilan PJ, Tsakiridis T and Tsiani E: Facilitative glucose transporters: Implications for cancer detection, prognosis and treatment. Metabolism 65: 124-139, 2016.

81. Masoud GN and Li W: HIF-1 $\alpha$ pathway: Role, regulation and intervention for cancer therapy. Acta Pharm Sin B 5: 378-389, 2015

82. Sertel S, Eichhorn T, Simon CH, Plinkert PK, Johnson SW and Efferth T:Pharmacogenomicidentification ofc-Myc/Max-regulated genes associated with cytotoxicity of artesunate towards human colon, ovarian and lung cancer cell lines. Molecules 15: 2886-2910, 2010.

83. Miller DM, Thomas SD, Islam A, Muench D and Sedoris K: c-Myc and cancer metabolism. Clin Cancer Res 18: 5546-5553, 2012.

84. Leśniak W: Epigenetic regulation of S100 protein expression Clin Epigenetics 2: 77-83, 2011.

85. Woodham AW, Da Silva DM, Skeate JG, Raff AB, Ambroso MR, Brand HE, Isas JM, Langen R and Kast WM: The S100A10 subunit of the annexin A2 heterotetramer facilitates L2-mediated human papillomavirus infection. PLoS One 7: e43519, 2012.

86. Dziduszko A and Ozbun MA: Annexin A2 and S100A10 regulate human papillomavirus type 16 entry and intracellular trafficking in human keratinocytes. J Virol 87: 7502-7515, 2013. 
87. Woodham AW, Taylor JR, Jimenez AI, Skeate JG, Schmidt T, Brand HE, Da Silva DM and Kast WM: Small molecule inhibitors of the annexin A2 heterotetramer prevent human papillomavirus type 16 infection. J Antimicrob Chemother 70: 1686-1690, 2015.

88. Litwin TR, Clarke MA, Dean M and Wentzensen N: Somatic host cell alterations in HPV carcinogenesis. Viruses 9: 206, 2017.

89. Stiasny A, Freier CP, Kuhn C, Schulze S, Mayr D, Alexiou C, Janko C, Wiest I, Dannecker C, Jeschke U and Kost BP: The involvement of E6, p53, p16, MDM2 and Gal-3 in the clinical outcome of patients with cervical cancer. Oncol Lett 14: 4467-4476, 2017.

90. Genova C, Rijavec E and Grossi F: Tumor microenvironment as a potential source of clinical biomarkers in non-small cell lung cancer: Can we use enemy territory at our advantage? J Thorac Dis 9: 4300-4304, 2017.
91. Tan Y, Ma SY, Wang FQ, Meng HP, Mei C, Liu A and Wu HR: Proteomic-based analysis for identification of potential serum biomarkers in gallbladder cancer. Oncol Rep 26: 853-859, 2011. International (CC BY-NC-ND 4.0) License. 